\title{
OBSERVATIONS OF BEACH-DUNE MORPHOGOLICAL RESPONSE TO STORM WAVES USING LIDAR BATHYMETRIC MAPPING IN A WAVE BASIN
}

Ramy Y. Marmoush, Queen's University, 13rym@queensu.ca

Ryan P. Mulligan, Queen's University, ryan.mulligan@queensu.ca

\section{INTRODUCTION}

Waves during major storms can cause significant changes to coastal morphology (Lee et al., 1998). The beach-dune system is known to be highly vulnerable to erosion when the wave run-up exceeds the threshold of the base of the dune in the collision regime, according to the Storm Impact scale defined by Sallenger (2000). Detailed bathymetric measurements are very difficult to obtain during storms due to the hazardous wave conditions. However, bathymetric surveys can be easily and intermittently performed during smaller scale physical model experiments (e.g., Hamilton et al., 2001) and high resolution can be achieved using laser scanning with Light Detection and Ranging (LIDAR) sensors (Smith et al., 2017). In the present study, a laboratory experiment of beach-dune morphology change is conducted in a rectangular wave basin that has recently been used to simulate erosion of a 2-dimensional sand dune (Berard et al., 2017). The objective of the present study is to investigate the 3-dimensional morphologic response of a sand beach-dune system to storm waves approaching at an oblique angle.

\section{EXPERMENT}

The experimental layout in the rectangular wave basin $(26.0 \mathrm{~m} \times 20.5 \mathrm{~m})$ is shown in Fig. 1. This is composed of offshore waves generated by the $10.5 \mathrm{~m}$ wide piston-type wave paddle, the beach-dune system, and the instruments. The paddle produces long-crested random waves with a Jonswap spectrum at the offshore boundary. The sensors include acoustic Doppler current meters (Nortek Vectrino Profilers, Nortek Aquadopp), pressure sensors (RBR duets), optical backscatter sensors (Campbell Scientific OBS3+), and a LIDAR scanner (FARO Focus ${ }^{5}$ ). Waves generated by the paddle propagate across the basin in a mean water depth of $\mathrm{h}=$ 0.5 at a $25^{\circ}$ incident angle to the $18.7 \mathrm{~m}$ long uniform beach shown in Fig. 2(top). The initial dune slope is constructed at 1:1.5 (above the still water level, SWL) and the beach slope is 1:5 (below SWL). The beach is composed of uniform silica sand with a mean grain size of $D_{50}=0.1 \mathrm{~mm}$. The waves break in the surf zone, and over time cause erosion of the dune shown in Fig. 2(bottom).

In this experiment, a storm is simulated using five different steps in wave energy. These are defined by wave time series with different bulk statistics including the significant wave height $(\mathrm{Hs})$, peak wave period $(\mathrm{Tp})$ and duration $(\mathrm{t})$. The wave conditions are characterized by a range of statistical bulk properties of $\mathrm{Hs}(7-11 \mathrm{~cm})$ for a constant $\mathrm{Tp}(1.5 \mathrm{~s})$ and varying duration (10-20 $\mathrm{min})$ at each step to simulate changes in the storm energy over time.

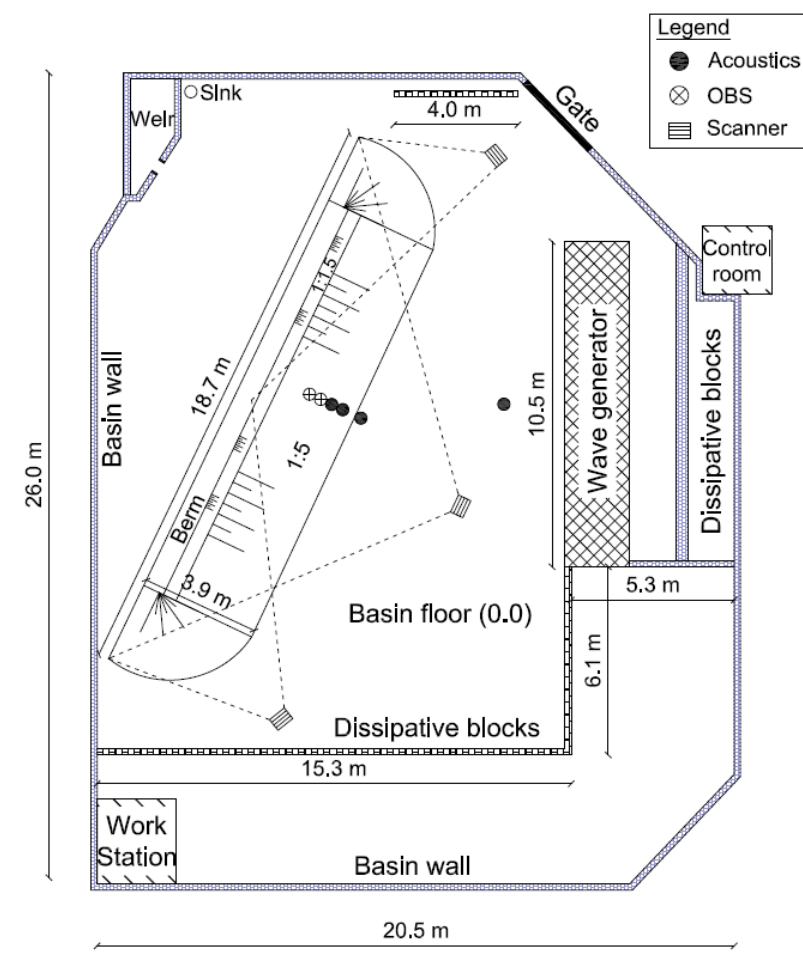

Figure 1 - Experimental layout in the wave basin showing the beach, wave paddle, dissipative boundaries and instruments locations. Wave propagation is right to left.
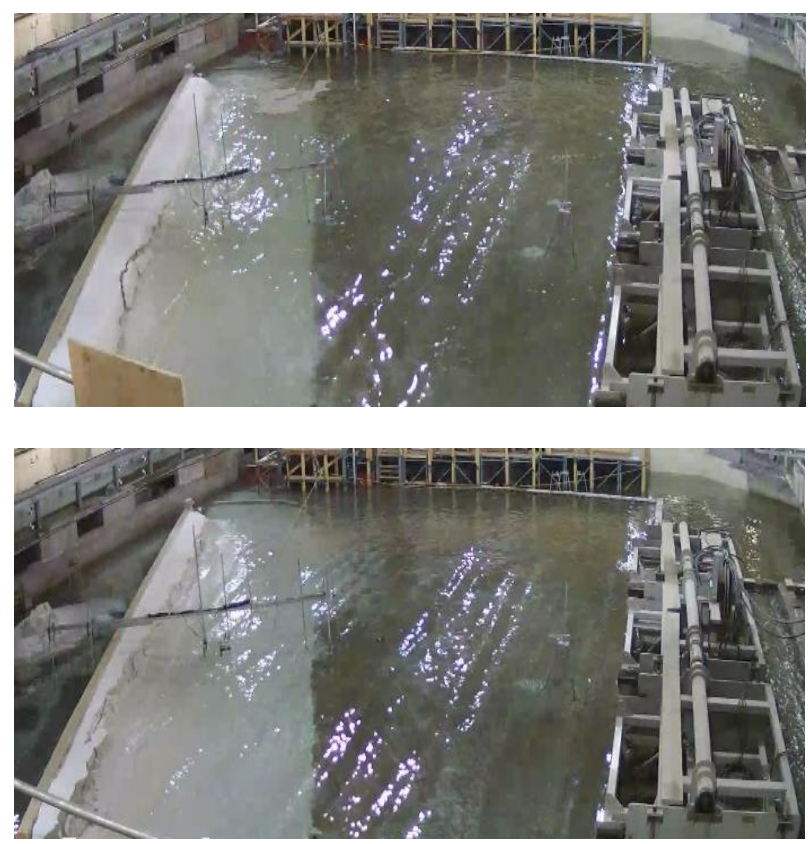

Figure 2 - View of the experimental domain from above the gate shown in Fig. 1, during early(top), and late (bottom) steps of the simulated storm event. 
The experimental goal is to measure the changes to the beach morphology induced by nearshore hydrodynamics over time. This is achieved by stopping the waves, draining the basin, and scanning the morphology from three different angles using the LIDAR sensor at $0.1 \mathrm{~mm}$ spatial resolution. A total of six bathymetry scans were performed, including one at the start of the experiment and one after each change in the wave conditions. The change between each 3-dimensional bathymetric dataset allows for computation of the bedload transport and bedform evolution. Local observations of bottom elevation distance change with acoustic sensors and suspended load concentration using optical backscatter sensors complete the full picture of sediment transport and morphology change along the beach. High frequency acoustic measurements of nearshore and offshore hydrodynamics are collected to monitor changes in waves and currents throughout the storm.

\section{RESULTS}

The high resolution LIDAR data reveal major morphological change of the beach-dune system during the storm simulation. A selected result is shown in Fig. 3, indicating the change in bed elevation caused by the waves. The most notable change is severe erosion of the dune toe and formation of a beach scarp, especially where the waves are the largest ( $y=10.0 \mathrm{~m}$ to $4.0 \mathrm{~m}$ ). The sand removed from the dune is transported by the alongshore currents. The sand is deposited where wave energy is lower ( $y=4.0 \mathrm{~m}$ to $-2.0 \mathrm{~m}$ ) in a sandbar. The cross-shore beach profiles in Fig. 4 show the formation of the beach scarp with very steep (almost vertical) face and milder slope at the toe similar to the initial beach slope. Over the storm, the erosion causes the location of the beach scarp to extend landward and sand accumulates on the sandbar. These experimental observations are used to determine the sand volumes and transport rates during morphologic evolution of a beach-dune system, at important time steps throughout a storm event.

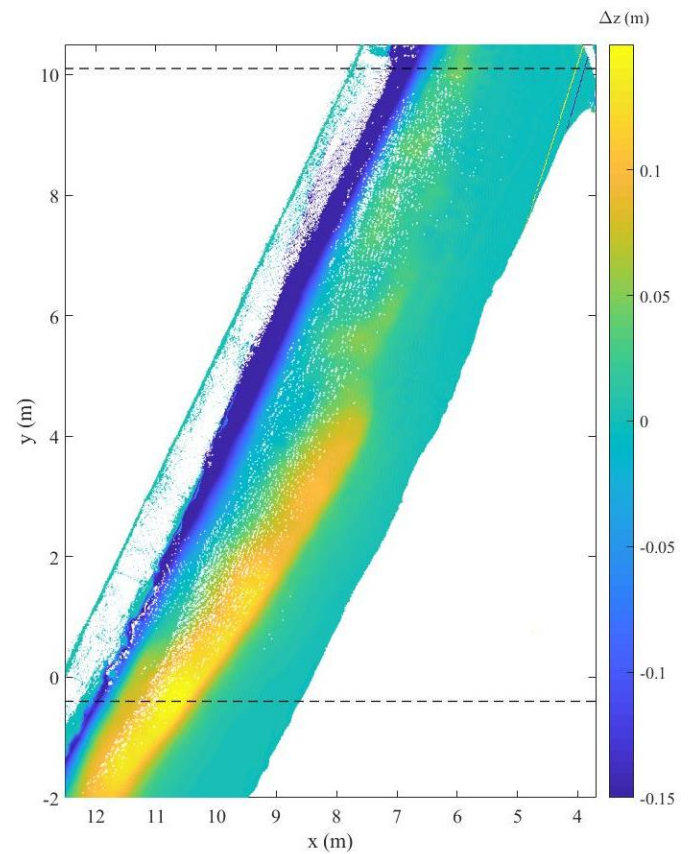

Figure 3 - Difference LIDAR measurements indicating the change in beach bathymetry after the storm. Dashed lines indicate the wave paddle width where the paddle is located at $x=0.0 \mathrm{~m}$ and extends from $\mathrm{y}=-0.4$ to $10.1 \mathrm{~m}$.

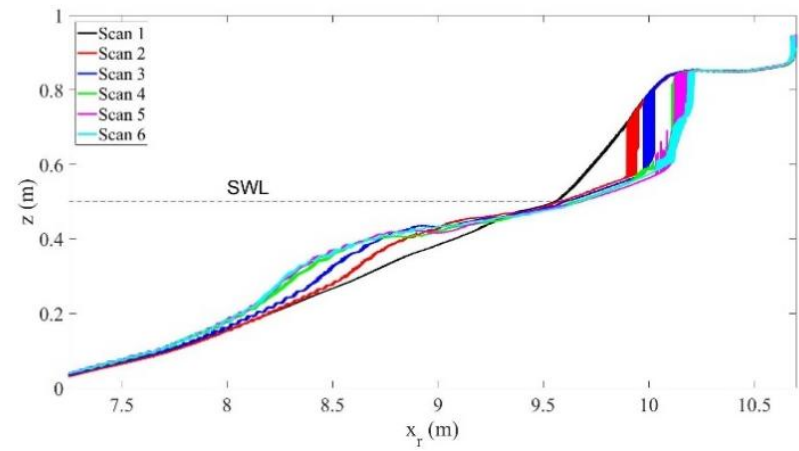

Figure 4 - Typical cross-shore beach profiles from each LIDAR scans at $y=5.0 \mathrm{~m}$ above the basin floor elevation at $\mathrm{z}=0.0 \mathrm{~m}$.

\section{REFERENCES}

Berard, Mulligan, da Silva, Dibajnia (2017): Evaluation of XBeach performance for the erosion of a laboratory sand dune, Coastal Engineering, 125, 70-80.

Hamilton, Ebersole, Smith, Wang (2001): Development of a large-scale laboratory facility for sediment transport research, Technical Report, ERDC/CHL, TR-01-22.

Lee, Nicholls, Birkemeier (1998): Storm-driven variability of the beach-nearshore profile at Duck, North Carolina, USA, 1981-1991, Marine Geology, 148, 163-177.

Sallenger (2000): Storm impact scale for barrier islands, Coastal Research, 16(3), 890-895.

Smith, Mohr, Chader (2017): Laboratory experiments on beach change due to nearshore mound placement, Coastal Engineering, 121, 119-128. 